DOI: $10.14451 / 1.193 .414$

\title{
ТЕНДЕНЦИИ ДИВЕРСИФИКАЦИИ ЗАРУБЕЖНЫХ НЕФТЕГАЗОВЫХ КОМПАНИЙ И ВОЗМОЖНОСТЬ ИСПОЛЬЗОВАНИЯ ИХ ОПЫТА В РОССИИ
}

\section{(C) 2020 Сенченкова Дарья Владиславовна}

аспирант кафедры экономики и управления предприятиями и производственными комплексами Санкт-Петербургский государственный экономический университет, Россия, Санкт-Петербург

E-mail: dsenchenkova@mail.ru

\section{(c) 2020 Головинов Петр Николаевич}

кандидат экономических наук, соискатель кафедры экономики и управления предприятиями Санкт-Петербургский государственный экономический университет, Россия, Санкт-Петербург

E-mail:p.golovinov@gmail.com

В данной статье описаны тенденции диверсификации зарубежных нефтегазовых компаний и оценена возможность заимствования их опыта отечественными нефтегазовыми компаниями, которые вынуждены развиваться в современных условиях финансовых ограничений и санкций. Также в статье представлен анализ текущей ситуации на мировом нефтегазовом рынке к началу 2020 года.

Ключевые слова: диверсификация, слияния и поглощения, $m \& a$, технологические партнерства

За прошедшее десятилетие цены на нефть колебались от самых высоких значений в период с 2011 до середины 2014 года до минимума в период с 2014 по 2017 год. В начале 2020 года возникли новые препятствия для нефтегазовой отрасли, которые значительно затрудняют процесс составления прогноза развития отрасли и создают новые вызовы для компаний нефтегазового сектора для сохранения устойчивости в нестабильный период. Несмотря на мировые тенденции перехода от ископаемых видов топлива, к неископаемым, в частности к возобновляемым источникам энергии, по прогнозу Международного энергетического агентства к 2040 году 75\% спроса будет составлять ископаемое топливо, поэтому у нефтегазовых компаний есть потенциал для развития в будущем [1].

K началу 2020 года нефтегазовый рынок характеризуется следующими основными чертами [2].

1) Наличие торгово-экономических препятствий, которые вызывают неопределенность для топливных рынков. По прогнозу Deloitte, ожидается замедление экономического роста в мире, что может оказать существенное влияние на спрос на топливо [1]. Также существенное влияние может оказать внедрение новых требований Международной морской организации (International Maritime Organization) с 1 января 2020 года, согласно которым содержание серы в морском мазуте должно быть уменьшено с 3,5\% до 0,5\% [3]. Неудачные переговоры стран ОПЕК+ в марте 2020 года также не способствовали улучшению ситуации на рынке.

2) Повышение безопасности мировой поставки нефти. Произошедшая атака на нефтяные объекты Саудовской Аравии 14 сентября 2019 года сократила добычу на 5,7 миллиона баррелей в сутки [4]. Несмотря на быстрое восстановление поставок нефти, возникшая ситуация показала необходимость повышения безопасности инфраструктуры предприятий для минимизации риска сбоя мировых поставок энергоресурсов в будущем.

3) Рост объемов потребления СПГ. В 2019 году мировой спрос на СПГ вырос на $12,5 \%$, достигнув своего максимального значения - 359 миллионов тонн. По прогнозу Shell, к 2040 году спрос на СПГ может составить до 700 миллионов тонн, на СПГ-бункеровку превысит 30 миллионов тонн, основными потребителями будут Китай, страны Южной и Юго-Восточной Азии [5]. Все это делает данное направление в нефтегазовой отрасли перспективной и привлекательной для потенциальных инвесторов.

4) Осторожность инвесторов. По сравнению с 2015-2016 годами, когда инвестиции в нефтегазовый сектор сократились почти в два раза с уровнем 2014 года, последние три года наблюдается стабилизация инвестиций. Наблюдается медленный ежегодный рост в среднем на 5-6\% [6]. Такая осторожность инвесторов связана с низкими и волатильными ценами на нефть за последние годы и ограниченным ростом спроса 
в долгосрочной перспективе.

5) Усиление тенденций энергетического перехода. По данным Института энергетических исследований Российской Академии наук и Центра энергетики Московской школы управления СКОЛКОВО мир входит в этап 4-го энергетического перехода, который заключается в широком использовании возобновляемых источников энергии и вытеснению ископаемых видов топлива. По их оценке, нефтяной рынок может потерять от 870 до 1800 миллионов тонн нефтяного эквивалента из-за роста эффективности транспортных средств и распространения транспорта на альтернативных источниках энергии [7]. Для сохранения устойчивости в будущем нефтегазовым компаниям необходимо перестраиваться в настоящее время.

Таким образом, современные условия развития нефтегазовой отрасли привели к значительным финансовым ограничениям компаний, что способствует поиску дополнительных денежных средств за пределами нефтегазового сектора. Исследователи PwC выделяют три основные тенденции диверсификации нефтегазовых компаний за рубежом [8]:

- продолжение развития в сфере ископаемого топлива;

- диверсификация своего бизнеса;

- отказ от нефтегазового бизнеса и полный переход в сферу возобновляемых источников энергии (ВИЭ).

Продолжение развития в сфере ископаемого топлива практикуется нефтегазовыми компаниями среднего размера. Основными направлением инвестиций является добыча нефти и газа. Американская нефтегазовая компания Occidental Petroleum продолжает инвестировать в расширение нефтегазовых активов, при это совершая небольшие инвестиции в развитие нефтехимических технологий (carbon sequestration technology). Другая американская компания EOG Resourses предпочла отказаться от услуг нефтесервисных компания и стала самостоятельно обеспечивать себя необходимыми ресурсами и услугами для контроля своих затрат. Saudi Aramco, Equinor, Total и Royal Dutch Shell совершают значительные инвестиции в развитие технологий, связанных с сокращением вредных выбросов в атмосферу.

Диверсификация бизнеса нефтегазовых компаний предполагает приобретение бизнеса и активов, напрямую не связанных с их основ- ным видом деятельности. Наиболее перспективными направлениями диверсификации являются проекты, связанные с развитием следующих отраслей: нефтехимии, добычи, переработки и поставки природного газа и генерацией возобновляемых источников энергии. В 2015 году Royal Dutch Shell приобрела BG Group для расширения своего влияния в секторе СПГ. В 2012 году Total совместно с EREN Group создала подразделение Total EREN, которое занимается развитием возобновляемых источников энергии. Увеличение инвестиций в нефтехимическую отрасль обусловлено прогнозом Международного Энергетического Агентства, которое оценивает, что к 2030 году треть спроса на добычу нефти, а к 2050 году половину спроса будут составлять продукты нефтехимии, основными импортерами которых будут страны Средней Азии и Китая [1].

Отказ от нефтегазового бизнеса и полный переход в сферу возобновляемых источников энергии является радикальным шагом для большинства компаний, однако уже есть реальные примеры по реализации данной тенденции диверсификации. Крупнейшая энергетическая компания Дании Dong Energy полностью изменила концепцию своего бизнеса в пользу возобновляемых источников энергии. Переименовав себя в 2017 году в Orsted, компания поставила цель сократить выбросы углеводородов от добычи нефти и газа на 96\% к 2023 году [10]. Французская нефтегазовая компания GDF Suez (Engie) также изменила свою концепцию, став энергетической компанией, главной целью которой является устойчивое развитие энергетики.

Масштаб реализации мероприятий по диверсификации связан с размером компании. Очевидно, что крупные компании имеют больше денежных средств, поэтому могут позволить себе приобрести нужные активы, не разрабатывая их самостоятельно, минимизируя свои риски и финансовые издержки. Компании с меньшей финансовой гибкостью могут пересмотреть свое портфолио для высвобождения денежных средств, которые они смогут направить в более перспективные и инвестиционнопривлекательные проекты. Для небольших и независимых энергетических компаний возможным вариантом является создание альянсов, которые могут подразумевать собой слияние компаний или сотрудничество в рамках определенных проектов.

Одним из основных инструментов дивер- 
сификации являются сделки по слияниям и поглощениям (M\&A), представляющие собой вид финансовых операций, цель которых - объединение компаний в один хозяйствующий субъект для получения конкурентных преимуществ и максимизации стоимости этого субъекта в долгосрочной перспективе [11]. В 2019 году общая сумма сделок по слияниям и поглощениям составила 4094 млрд. долл. США [12]. В разрезе регионов наибольшая доля по операциям по слияниям и поглощениям приходится на Северную Америку - 50,7\%, страны EMEA - 25,1\%, страны Азиатско-Тихоокеанского региона - 22,0\%, страны Латинской Америки - 2,2\%. В разрезе секторов наибольшая доля сделок приходится на энергетический сектор - $18,1 \%$, промышленность и химическая отрасль $-13,4 \%$, технологический сектор - 12,5\% [13].

В 2019 году количество сделок на российском рынке слияний и поглощений выросло на $3 \%$, однако сумма сделок выросла на $21,5 \%$, составив 63 млрд. долл. США, что составляет $1,54 \%$ от общей суммы сделок по слияниям и поглощениям в мире. Данный рост был достигнут за счет крупных сделок в нефтегазовом секторе. Из 10 крупнейших сделок на российском рынке 6 сделок относятся к нефтегазовому сектору. Всего доля сделок в нефтегазовом секторе России в общей сумме сделок составляет 34\% [14].

Инструмент слияния и поглощения, распространенный в мировой практике, способствует привлечению иностранных инвестиций. Так, размер иностранных инвестиций в 2019 году в нефтегазовую отрасль составил 9 млрд. долл. США [14]. Наибольшую часть этих инвестиций составляет покупка 30\% долей участия в проекте «Арктик СПГ-2» компаниями Japan Oil, Mitsui \& Co, CNOOD и CNODC.

Другим инструментом диверсификации является технологическое партнерство, представляющее собой форму кооперации, подразумевающую передачу технологий, обмен знаниями, рисками, ресурсами для решения технологических задач, которые экономически целесообразно решать сообща [15]. Данный инструмент еще не настолько распространен в России по сравнению со сделками по слияниям и поглощению. Основные преимущества технологического партнерства состоят в том, что партнерство не предполагает реорганизацию юридических лиц, работа заключается в рамках одного проекта с определенными объемами инвестиций, прав и обязанностей, рисками и долями в прибыли. Технологическое партнерство ускоряет процесс создания конкурентного преимущества и получения доступа к новым рынкам. Также оно может иметь разнообразную конфигурацию, объединяя самых разных стейкхолдеров: государство, нефтегазовые компании, сервис и оборудование, разработчиков технологий.

По оценке KPMG, Россия является одним из наиболее инвестиционно-привлекательных регионов мира для инвестиций в нефтегазовую отрасль, которая обладает следующими характерными чертами: стабильность политического режима, готовность государства и крупных компаний к работе с иностранными партнерами, относительно низкая себестоимость добычи, развитая инфраструктура и отсутствие административных и регулятивных барьеров для разведки и разработки новых месторождений. Дополнительным преимуществом является наличие эффективных мер государственной поддержки и относительно низкий порог вхождения в отрасль по сравнению с другими странами мира [16]. Таким образом, у российской нефтегазовой отрасли есть потенциал развития в будущем, в современных условиях финансовых ограничений и санкций диверсификация бизнеса отечественных нефтегазовых компаний по опыту и примеру зарубежных нефтегазовых компаний позволит им и их стейкхолдерам быстрее и эффективнее реализовывать сложные проекты, минимизируя свои риски.

\section{Библиографический список}

1. World Energy Outlook 2019 [Электронный ресурс]: официальный сайт Международного энергетического агентства - Режим доступа: https://www.iea.org/reports/world-energy-outlook-2019

2. 2020 oi, gas and chemical industry outlook [Электронный ресурс]: официальный сайт консалтинговой компании Deloitte - Режим доступа: https://www2.deloitte.com/ch/en/pages/energy-and-resources/articles/oil-andgas-industry-and-chemicals-industry-outlook.html

3. Sulphur 2020 - cutting Sulphur oxide emissions [Электронный ресурс]: официальный сайт Международной морской организации - Режим доступа: http://www.imo.org/en/mediacentre/hottopics/pages/sulphur-2020. aspx 
4. Incidents at Abqaiq and Khurais [Электронный pecypc]: официальный сайт национальной нефтяной компании Саудовской Аравии Saudi Aramco - Режим доступа: https://www.saudiaramco.com/en/news-media/ news/2019/incidents-at-abqaiq-and-khurais

5. Shell LNG Outlook 2020 [Электронный ресурс]: официальный сайт нефтегазовой компании Shell - Peжим доступа: https://www.shell.com.ru/shell-media-center/shell-news/2020-news-and-media-releases/lngoutlook-2020/_jcr_content/par/textimage.stream/1582614835207/c71d19446a1aca47f5444a4c6b7395386d 8a1466/shell-lng-outlook-2020-infographic.pdf

6. Investment in upstream oil and gas [Электронный ресурс]: официальный сайт Международного энергетического агентства - Режим доступа: https://www.iea.org/reports/world-energy-investment-2019/fuel-supply

7. Прогноз развития энергетики мира и России 2019 [Электронный ресурс]: официальный сайт Центра энергетики Московской школы Управления СКОЛКОВО - Режим доступа: https:/energy.skolkovo.ru/downloads/ documents/SEneC/Research/SKOLKOVO_EneC_Forecast_2019-02_Rus.pdf

8. Oil and Gas trends 2019 [Электронный ресурс]: официальный сайт консалтинговой компании $\mathrm{PwC}$ - Режим доступа: https://www.pwc.com/gx/en/ceo-survey/2019/Theme-assets/reports/pwc-2019-ceo-survey-oil-andgas-report.pdf

9. World Energy Outlook 2019 [Электронный ресурс]: официальный сайт Международного энергетического агентства - Режим доступа: https://www.iea.org/reports/world-energy-outlook-2019

10. Our strategy [Электронный ресурс]: официальный сайт энергетической компании Orsted - Режим доступа: https://orsted.com/en/Sustainability/Our-strategy

11. Финансово-кредитный энциклопедический словарь / Под общей редакцией А. Г. Грязновой.- М.: Финансы и статистика, 2002.

12. 2019 Global M\&A Outlook [Электронный ресурс]: официальный сайт финансового холдинга J.P.Morgan Режим доступа: https://www.jpmorgan.com/global/cib/2019-ma-global-year-outlook

13. Global \& Regional M\&A Report 2019 [Электронный ресурс]: официальный сайт портала Merger Market - Peжим доступа: https://www.mergermarket.com/info/2019-global-ma-report-legal-league-tables

14. Рынок слияний и поглощений в 2019 году [Электронный ресурс]: официальный сайт консалтинговой компании KPMG - Режим доступа: https://home.kpmg/ru/ru/home/insights/2020/02/russian-2019-ma-overview. html

15. Технологические партнерства в нефтегазовом секторе: применим ли опыт мировой кооперации в России? [Электронный ресурс]: официальный сайт Центра энергетики Московской школы Управления СКОЛКОВО - Режим доступа: https://energy.skolkovo.ru/downloads/documents/SEneC/Research/SKOLKOVO_EneC_ Research02_2018.12.01_Rus.pdf

16. Рынок слияний и поглощений в 2019 году [Электронный ресурс]: официальный сайт консалтинговой компании KPMG - Режим доступа: https://home.kpmg/ru/ru/home/insights/2020/02/russian-2019-ma-overview. html 